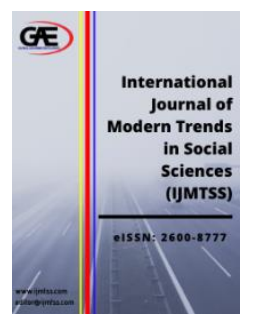

\author{
INTERNATIONAL JOURNAL OF \\ MODERN TRENDS IN \\ SOCIAL SCIENCES \\ (IJMTSS) \\ www.ijmtss.com
}

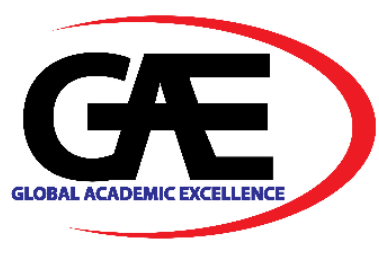

\title{
THE EFFECTIVENESS OF FOOD SECURITY DIMENSIONS ON FOOD SECURITY IN LANDLOCKED DEVELOPING COUNTRIES
}

\author{
Nur Marina Abdul Manap ${ }^{1 *}$ \\ 1 Department of Economics, Finance and Banking (SEFB), Universiti Utara Malaysia, Malaysia \\ Email: nurmarina@uum.edu.my \\ * $\quad$ Corresponding Author
}

\begin{abstract}
Article Info:
Article history:

Received date: 02.11.2020

Revised date: 11.11 .2020

Accepted date: 02.12.2020

Published date: 09.12.2020

\section{To cite this document:}

Manap, N. M. A. (2020). The Effectiveness of Food Security Dimension on Food Security in Landlocked Countries. International Journal of Modern Trends in Social Sciences, 3 (14), 116-128.
\end{abstract}

DOI: $10.35631 / \mathrm{IJMTSS} .3140010$

This work is licensed under CC BY 4.0

\begin{abstract}
:
Food security is an important issue that has been discussed all over the world Achievement in food security is based on the Food and Agriculture Organization (FAO policy) and depends on four important indicators known as availability, accessibility, utilization, and stability. This paper examines the effectiveness of the food security dimension on food security in Landlocked Developing Countries. The static panel data was adopted using a fixed-effect model to measure the effectiveness of food security dimensions on DES. The findings of this study showed that food security dimensions played a very important role in affecting the DES in landlocked developing countries. An increase in food availability, food accessibility, food utilization, and food stability were found to positively impact food security achievement in Landlocked developing countries.
\end{abstract}

Keywords:

Food Security, Availability, Accessibility, Utilization and Stability

\section{Introduction}

Food is among humans' basic needs for social development. Food can be defined as an element that people consume that provides nutrients such as carbohydrates, fats, proteins, vitamins, and minerals for the body. It originates from either plant or animal sources. Food absorbed by the body helps to produce energy and stimulate healthy growth. There are two types of nutrients and the first is micronutrients, which are needed in the human body in small amounts and contain vitamins and minerals. The second is macronutrients that contain carbohydrates, 


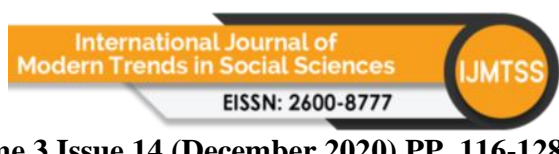

Volume 3 Issue 14 (December 2020) PP. 116-128

DOI 10.35631/IJMTSS.3140010

protein, and fats needed in large amounts by the human body. In the past, people traditionally acquired food through primitive hunting and farming methods. Today, humans' methods for food collection have changed considerably. Most traditional and primitive ways have become side lined by the introduction of intensive industrial farming and agriculture. Achievement in cultivation methods has also helped to substantially increase production capacity. Food is now a product supplied by industries operated by multinational industries and corporations.

Food is essential for survival, but the question of whether enough food is available for the people of the world is subject to population growth. If the availability of food is not sufficient to fulfil humans' basic needs, it can cause global food shortages and if unchecked could lead to major crises and present major challenges to humanity's food security. Factors such as climate change, natural disaster, overpopulation, food crisis, higher food prices, and diminishing resources have worsened the food shortage situation and have become global food security issues.

\section{Background of Study}

Food sufficiency is crucial to reduce the problem of undernourished and hungry people, especially in developing countries. The Food and Agriculture Organization (FAO) indicated that the global level of Prevalence of Undernourished (POU) is below 11 percent, while the total number of undernourished has increasing slowly where over 820 million people suffer from hunger, which is about one in every nine people in the world is suffer from hunger (FAO, 2019). Therefore, achieving sufficiency of food is very important to fulfil humans' basic needs globally and improve food security in developing countries.

Food security is one of the critical issues that have been seriously discussed in terms of prevention of malnutrition, hunger, and famine, especially in landlocked developing countries. Food security has been defined as a situation when all people at all times have both physical and economic access to sufficient food to meet their dietary needs for productive and healthy life (USAID, 1992). FAO has identified four important indicators to measure the achievement of food security, namely food availability, food accessibility, food utilization, and food stability. Moreover, one or more of these three important indicators need to play their roles to improve food security in developing countries, which is to provide sufficient availability of food, easy accessibility of food, and utilization of food to sustain the achievement of food security, especially in developing countries (USAID, 1992). However, FAO has added food stability as additional indicators that playing an important role to sustained food security.

As mention previously, there are four important dimensions for measuring food security. Firstly, food security is based on the physical availability of food. All nations need to elucidate the availability of sufficient quantities of good quality foodstuffs. Food availability plays a critical role in providing the necessary nourishing elements to citizens of every country. This quantity of food is in the form of supplies through domestic production, stock levels, food imports, and food aids. Food security and human development have a strong relationship through food production (Conceicao et al., 2011). However, fully depending on food production to fulfil one's food needs is difficult to achieve due to resource constraints and climate change problems. Nevertheless, relying on both imports and food production can help countries improve and achieve food security (Magnan et al., 2011). Moreover, there is no strong relationship between food supply and food production (Wagstaff, 1982). This shows that food production is not the only indicator to solve food shortage and achieve food security, 


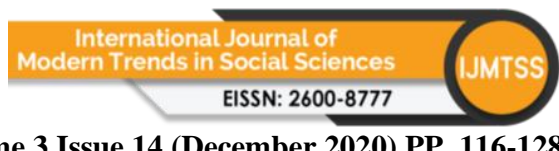

Volume 3 Issue 14 (December 2020) PP. 116-128

DOI 10.35631/IJMTSS.3140010

but food production and food imports need to play a simultaneous role in achieving food security in developing countries.

Additionally, sufficiency of food also depends on food aid. Food aid plays an important role to overcome famine and hunger, especially in developing countries. It can be classified into two categories where firstly, food aid is a key source for short-term emergencies, such as during earthquake, hurricane, drought, and war. Secondly, food aid is programmed to resolve deficiencies of food in the medium term. Food aid plays a vital role in emergency situations and also solves food shortage issues in long-term situations (del Ninno et al., 2007). There are several factors that have influenced the availability of food such as inappropriate agriculture knowledge, technologies and practices, unsuitable economic policies (pricing, marketing, tax, and tariff), lack of foreign exchange, inadequate agriculture inputs, population growth rates that offset increased production or imports, marketing and transportation systems that inhibit the cost-effective movement of food from source to need, and the inability to predict, assess, and cope with emergency situations, thus, interrupting food supplies, along with natural resource constraints and problems relating to the climate and diseases.

The next dimension is economic and physical access to food, concerning access to adequate resources for acquiring appropriate food for a nutritious diet. The physical and economic accessibility of food is important to individuals and families to achieve food security (Kennedy et al., 2004). There are two types of food accessibility. Firstly, is physical food accessibility in terms of transportation, infrastructure, storage, transformation, and marketing of food commodities. Secondly, is the economic accessibility in terms of purchasing power and household income, which is considered the most important indicator affecting people's accessibility to healthy food. In addition, households also face accessibility constraints to individual food access including inadequate aggregate economic growth, lack of job opportunities, lack of incentives to become a productive participant in the economy, negative impact of national economic policies, inadequate training or job skills, and lack of income streams.

Food utilization also plays a key role in food security. Utilization is an important element of food security and is usually known as the way the body makes the most of various nutrients found in food. Furthermore, food utilization also shows that food is properly used through the employment of proper food processing and storage techniques, and adequate knowledge of nutrition and childcare techniques. Utilization has an impact on food security through adequate diet, clean water, sanitation, and health care to enable people to reach a state of nutritional wellbeing where all their physiological needs are met. Clean water and sanitation are very important in poor and developing countries to achieve a healthy life (Mara, 2003). The constraints to food utilization include nutrient losses associated with food preparation and inadequate knowledge and practice of healthy techniques. Based on sanitary and phytosanitary measures, sanitation services are very important to achieve food safety and food security (WTO, 1998).

Finally, the last dimension is food stability. There are three important indicators to measure food stability. The first is to measure the impact of food price on food security through food import channel. The second indicator is to measure the impact of land irrigation on food security through food production channel and lastly is the impact of political stability to food security in developing countries. There is very limited evidence to prove and research done to determine that these four dimensions will influence food security improvement. The questions that arise from this issue include whether these four dimensions will benefit food security in Copyright $\odot$ GLOBAL ACADEMIC EXCELLENCE (M) SDN BHD - All rights reserved 


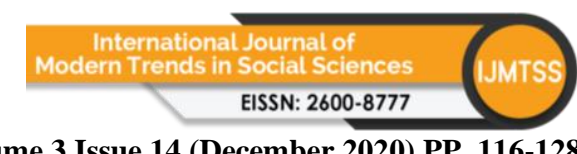

Volume 3 Issue 14 (December 2020) PP. 116-128

DOI 10.35631/IJMTSS.3140010

selected landlocked developing countries. The objective of this paper is to analyse the improvement of food security through food security dimensions' effectiveness in landlocked developing countries.

\section{Literature Review}

FAO has identified four important dimensions for improving food security at the national level. These dimensions are availability, accessibility, utilization, and stability. Food availability is one of four dimensions of food security and consists of food production, food imports, and food aid to fulfil the minimum requirement per capita. Food security and human development have a strong relationship through food production (Conceicao et al., 2011). Africa needs sufficient food supplies to feed 18 million additional people every year. These food supplies are essential to reduce undernourishment. Africa has a huge potential to increase food production, reduce the gap in crop yield, and decrease food insecurity problems. In addition, food production also has a huge impact on food security in China (Zhang, 2011). Zhang's study has revealed that China needs to feed $20 \%$ of the global population with its minimum resources, which consist of 5\% of the world's water resources, $7 \%$ of the global arable land, and limited natural resources. Yet, with minimum resource production, China can supply a lot of food; in 1949 it supplied $200 \mathrm{~kg}$ per capita, an amount that doubled to $400 \mathrm{~kg}$ per capita in the 1990s. The increasing amount of food production has reduced hunger and famine in China. This situation follows a $250 \%$ population increase and a $450 \%$ increase in total grain production during the aforementioned period.

Some studies have been conducted to help minimize the dependence on food imports and increase food self-sufficiency (Magnan et al., 2011). Achieving 100\% food self-sufficiency is difficult for several reasons, including resource constraints and climate change problems. However, relying on both food imports and food production can help countries improve and achieve food security Magnan et al. (2011) have presented new models to capture the tradeoffs between cereal production and high value crop (HVC) production at the national level. These models have been built due to high and volatile cereal prices, so the governments of food-importing countries must minimize their dependence on food imports and rely on selfsufficiency in terms of food production. National food security is reinforced, focusing on minimizing reliance on food imports, increasing food production, generating foreign exchange to encourage the production of HVCs for export, and ensuring appropriate market channels to market all foods. Poor farmers who do not have access to HVC markets are highly affected by increases in staple food prices. These farmers need to increase their own staple food production to counter higher prices, which means they must sacrifice land that has been used to grow fruits and vegetables. The World Bank's World Development Review has provided a new strategy to solve the poor farmers' problems by introducing a new strategy for accessing HVCs. With access to HVC markets, farmers can increase their cereal production by growing fewer staple crops and increasing HVCs. This strategy will increase farmers' income and raise their purchasing power of staple foods, despite rising prices.

Generally, certain countries will be classified as experiencing food insecurity when they face famine and hunger. Such countries depend not only on domestic food production but also rely on food aid and food imports as their main sources of food sufficiency. Moreover, there is no strong relationship between food supply and food production (Wagstaff, 1982). This shows that food production is not the only indicator to solve food shortage and food security problems, but food production and food imports must play a simultaneous role in overcoming food insecurity problems. Commonly, food shortage problems occur in low-income countries. Copyright $\odot$ GLOBAL ACADEMIC EXCELLENCE (M) SDN BHD - All rights reserved 


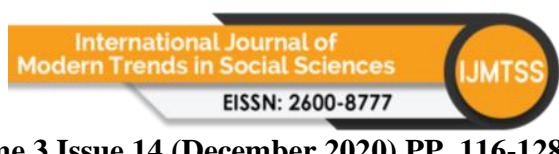

Volume 3 Issue 14 (December 2020) PP. 116-128

DOI 10.35631/IJMTSS.3140010

Surprisingly, this current study has shown that middle-income countries are more dependent on food imports than low-income countries. Based on the Standard International Trade Classification, developing countries are classified as net food exporters of commercial food products such as coffee, cocoa, tea, spices, sugar, and tropical fruits and are also known as net food-importing countries because of their lack of staple food production.

Furthermore, Morrison (1984) has analysed the determinants and trends of cereal imports in developing countries. These determinants are based on structural long-term factors and shortterm factors. The structural long-term factors are determined by the level of income per capita in those countries. A country classified as having a higher per capita income tends to have a higher cereal import per capita. Increases in Gross Domestic Product (GDP) per capita will raise the proportion of middle-class individuals; reduce the labor force in the agriculture sector because of increasing population migration to urban areas, and decrease food production because of ecological constraints, such as problems with irrigated land, drought, and landlocked countries. All these factors will contribute to the increasing demand for food imports to maintain domestic per capita food consumption.

The temporary, short-term factors that determine the changes in cereal food imports are caused by the instability of domestic food production, which is caused by climate change problems such as flood and drought. These situations lead to inefficiency of arable land, problems with irrigated land systems, and will cause a reduction in domestic food production and an increase in food imports to maintain the sufficiency of food. Dong and Veeman (1995) have agreed with Morrison (1984) and added that the increasing dependence on food imports is linked to three factors. The first factor is that an increase in income will cause an increase in demand for a better diet. Secondly, an increase in foreign exchange will cause an increase in food import demand, and lastly, dependence will be influenced by the relative cost of grain imports. However, a major contributor in determining food imports is a lack of domestic production and an improvement in diet, which is caused by an increase in income.

The second dimension of food security is accessibility, which is based on two important issues related to physical access in terms of paved roads and economic access in terms of purchasing power parity. These two issues play an important role in determining food accessibility to improve food security at the national level. The World Bank (1997) discovered that paved roads have a huge impact on the agriculture sector. For example, Chad has only $263 \mathrm{~km}$ of paved roads, $7 \%$ of which represents the main-priority road networks. However, only $37 \%$ of the main-priority road networks in Chad are in good condition, while $63 \%$ are inaccessible, due to significant damage caused by heavy vehicles during the rainy season. Hence, the major producers of grain in Chad must find ways to market their grains, because the country experiences six to eight months of rain every year, during which many of the roads are impassable. To overcome this problem, Chad's government has minimized this deteriorating situation by imposing traffic restrictions on vehicles weighing more than 3.5 tons between May 1 and the end of the rainy season every year. According to World Bank report, improvements in market access in terms of paved roads have increased agriculture production, increased farmers' income, and improved food security in Chad.

Furthermore, Breisinger et al. (2010) have also classified paved roads as an indicator of improvement in food security. These authors have emphasized the impact of alternative road investment plans on access to market and food security in their study. The improvement of market access by upgrading $20,000 \mathrm{~km}$ of unpaved roads to gravel roads could increase the Copyright (C) GLOBAL ACADEMIC EXCELLENCE (M) SDN BHD - All rights reserved 


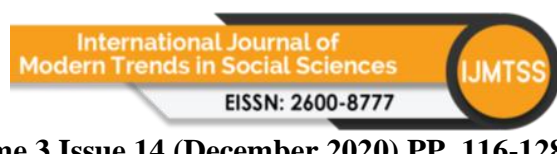

Volume 3 Issue 14 (December 2020) PP. 116-128

DOI 10.35631/IJMTSS.3140010

determination to upgrade or build road networks that would connect most rural areas to urban areas via paved roads. Investing in roads is driven by three important criteria i.e. improving access to people living in areas of great food insecurity, the prevalence of food insecurity, and connecting secondary networks to secondary cities. Additionally, the total road network also plays a vital role in determining whether the countries are classified as having food security or food insecurity. Moreover, based on a comprehensive Liberian food security and nutrition survey in 2010, food insecurity problems are largely caused by low levels of investment in crop production, low education achievements, poor road networks, high price volatilities, and poor health infrastructure (World Food Programme, 2007).

However, Chen and Kates (1994) have found that economic access in terms of household income also plays a significant role in improving food security. These authors have classified food security as sufficient food production to feed the population. Measurements of undernourished individuals, who are classified according to their inadequate dietary intake, are based on household access by income, expenditure, or consumption. The achievement of food security does not highly depend on the availability of food but is based on a few factors such as income distribution, dietary needs, food losses, and waste.

Economic access in terms of household income as an indicator of improving food security is supported by Haddad et al. (1994). They examined suitable indicators for measuring food security and monitoring nutrition. This current study provides a new conceptual framework and identifies alternative indicators for measuring food and nutrition security. These alternative indicators for measuring household food security and nutrition comprise three important categories. The first category comprises the demographic variables, such as household size, migration, ethnicity, and age or gender of the individuals. Next, are the market access variables such as household income sources, changes and flows of income, access to credit, land ownership, and sales of assets. The third category consists of proximate determinants of household food security and preschool nutritional status. The proxy variables that have been used to measure pre-schoolers are birth order, mother's age at birth, prenatal education, and breastfeeding patterns.

The next dimension of food security is known as food utilization and is based on the quality and safety of the food a person eats and how well people transfer it from food to nutrition and energy. Food utilization needs sufficient energy, essential nutrients, potable water, adequate sanitation, access to health services, proper feeding practices, and illness management. The World Food Programme (WFP) has identified some constraints in achieving food utilization, such as nutrient losses when preparing food, inadequate knowledge, and practice of health techniques and cultural practices that minimize the consumption of nutritious food. The United Nations has identified that nearly one billion people in the world have no access to clean water, and 2.6 million people globally do not have improved sanitation facilities. The impact of the lack of sanitation facilities and clean water has caused 925 million people to be categorized as chronically undernourished (Howard \& Bartram, 2003).

Food and water are essential requirements for human survival. Improving the quality of water and sanitation is crucial in poor and developing countries to ensure healthy lives (Mara, 2003). Poor and developing countries need to meet their targets for improving water supplies and sanitation by 2025 , whereby they need to provide access to water supplies for 2.9 billion people and access to improved sanitation for 4.2 billion people. Mara (2003) has found that all developing countries have simple, appropriate, effective, and affordable technologies to ensure Copyright (C) GLOBAL ACADEMIC EXCELLENCE (M) SDN BHD - All rights reserved 


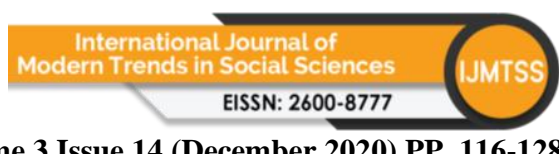

Volume 3 Issue 14 (December 2020) PP. 116-128

DOI 10.35631/IJMTSS.3140010

access to a good water supply and improved sanitation services for the people, but this expenditures spent on other needs. Water supplies and sanitation improvement facilities do not depend only on government expenditures; these facilities are also financed by investment, specifically public health investment (Watson, 2006). This current study as investigated the impact of a project aimed to improve sanitation infrastructures on a U.S. Indian reservation in 1960. Sanitation investments benefit countries because they can reduce the cost of supplying clean water to households. In the U.S., such projects help reduce diseases such as waterborne gastrointestinal diseases and infectious respiratory diseases among Native American infants.

In addition, Hubbard et al. (2011) have designed a community demand-driven approach to estimate the development of sustainable water and sanitation infrastructure. The authors' aim was to illustrate the strategy used by the CARE Peru and Cardozo community to fulfil local demand for water supplies and to make some improvements to water and sanitation facilities. The study has shown that the project has implemented the community demand-driven approach to the water supply distribution system and has extended up to $1.3 \mathrm{~km}$ into the southern zone of Iquitos and connected with the "condominial" water system. This project has influenced all the households in Cardozo that are connected to the water supply system after the "condominial" water installation and sewage system. In addition, the good water distribution system reduced diarrheal disease by $37 \%$ among children younger than five years old between 2003 and 2004.

Finally, the last dimension of food security is food stability. The achievement of food security at the national level, especially in developing countries, presents a huge challenge because these countries face many constraints; for example, vulnerability with food price and land irrigation issues. Food price instability contributes significantly to food insecurity problems. Food prices have an impact on food security at the household and national levels. Many people in developing countries have spent more than half of their income on food to fulfil their dietary energy needs. When world food prices drastically increase, it impacts these people, who will have to cut back on the quantity and quality of the food they buy. This situation causes food insecurity, famine, and undernourishment. The International Fund for Agricultural Development (IFAD) has identified two periods of global food price increases. The first was from 2007 to 2008, while the second was from 2010 to 2011; both were higher than increases in the early 1980 s.

Price stabilization is important for the improvement of food security and to solve problems related to higher food prices. Ahmad (1988) examined the rationale of price stabilization and its impact on food security. Moreover, his study developed a new approach to stabilizing food prices in Bangladesh. Some arguments have arisen about the validation of a theoretical position against price stabilization in Bangladesh. A rice price stabilization framework has been developed to mix public procurement, import, rationing, and open market operations to compress annual and seasonal prices. Price stabilization is used as an instrument for food security improvements and is crucial in reducing poverty and undernourishment in Bangladesh.

Myers (2006) has examined the cost of food price fluctuations in low-income countries. His study is linked to conventional welfare, where it measures the cost of food price vulnerability and its impact on economic growth and food security in low-income countries. This study has revealed that the cost of conventional welfare can be higher when fluctuations in food price have a negative impact on economic growth and causes a reduction in labor productivity and 


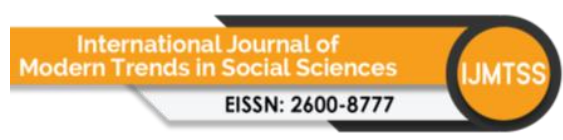

Volume 3 Issue 14 (December 2020) PP. 116-128

DOI 10.35631/IJMTSS.3140010

thus food security cannot be achieved. To overcome this problem, the author suggested a food price stabilization scheme to improve food security, welfare, and economic performance.

However, Wang (2010) found that food prices did not impact food security in China, because China had raised its residents' income the previous year. Increases in the retail food price index do not affect food security because of the concepts of income effects and substitution effects. Wang (2010) has conducted a study on food security, food prices, and climate change in China. The paper has determined the factors that influence food security, including the per capita disposable income of rural residents, the retail food price index, agricultural disaster area, sown area, and saving of urban and rural residents.

Another constraint that has an impact on food security is irrigation. Almost 195 million hectares of total irrigated areas are in developing countries because these countries still depend on irrigation systems to increase their food production. People in irrigated areas can derive direct benefits from increased crop intensities, improved yields, new technologies, and increased land values because of access to irrigation. In addition, people in irrigated areas can also enjoy indirect benefits of farm income increases, food price reduction, better nutrition, and increased clean water use for domestic purposes to ensure better health.

Besides, land irrigation is one of the indicators to measure food stability. Land irrigation is very important to increase food production and improve food security. Based on a previous study about irrigation and food security in the 21st century (Carruthers et al., 1997), this present study has found that irrigation plays an important role in increasing and improving food production. Some changes must be made in terms of expansion of irrigation areas and water supplies, with continuous improvement in the efficiency of existing water supplies usage. However, if improvements in irrigated areas cannot be achieved, land resources will be under increased pressure and the process of environmental degradation will be hastened. Irrigation and water development strategies cannot be achieved due to a lack of knowledge about the relationship among water scarcity, food production, food security, and environmental sustainability.

Moreover, Hassan et al. (2000) carried out a study on the trade-off between economic efficiency and food self-sufficiency using Sudan's irrigated land resources. Sudan has changed its food production strategy to be more dependent on the irrigation sector to improve the food supply, due to food shortages that occurred during the 1980s, which were caused by drought and reduced availability of food. However, this food shortage ended in 1989, when crop yields under irrigated systems increased significantly. Hassan et al. (2000) carried out a domestic resource cost analysis to examine whether the expansion in irrigated wheat production was more efficient than Sudan's irrigated land resources usage for cotton. The study results showed that expenditure on irrigated wheat production in Gezira to ensure food self-sufficiency reduced employment opportunities and impacted economic efficiency. Irrigation systems are important for countries that face drought and erratic rainfall patterns. Ghana is an example of a developing country that has this problem (Burney \& Naylor, 2012). The agricultural sector is the main sector in Ghana, employing $86 \%$ of Ghanaians.

\section{Methodology}

This paper has employed the country fixed effects model because this model is suitable to consider unobserved individual characteristics that are assumed to be correlated with the error term. The fixed effects model was used to analyse the impact of fluctuating variables over time 


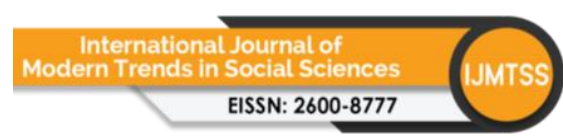

Volume 3 Issue 14 (December 2020) PP. 116-128

DOI 10.35631/IJMTSS.3140010

and to determine the relationship between the predictor variable and the outcome variable. Each country has its own characteristics that may or may not influence the predictor variables.

Meanwhile, the random effects model is an alternative for the fixed effects model to estimate coefficients of time-constant exogenous variable. The difference between the fixed effects model and the random effects model depends on whether the unobserved individual effect represents the elements that are correlated with the regressors in the model, notwithstanding whether the effect is stochastic or non-stochastic. The random effects model is more suitable if the error term or the differences across countries are related to the dependent variable. Timeinvariant variables can be included in the random effects model.

To identify which estimation was more suitable for this study, the Hausman test was run to choose between the random effects model and the fixed effects model. The null hypothesis of the test stated that there was no correlation between the individual effects and the explanatory variables. This implied that both random and fixed effects were consistent but only the random effect was efficient. Meanwhile, the alternative hypothesis stated that the individual effects were correlated with the explanatory variables, implying that only the fixed effects approach was consistent and efficient. Based on the Hausman test, the best choice for this study was the fixed effects model.

\section{Model Specification}

The FAO has identified four important dimensions of food security, which are availability, accessibility, utilization, and stability that play important roles in achieving food security, especially in developing countries. Nevertheless, the measurement is not directly through these four dimensions. Food availability is determined using food production, food import, and food aid. Besides, food availability measurement can also be based on food supply, which comprises food production, food import, and food aid. Meanwhile, purchasing power parity and road infrastructure are used to determine food accessibility. Next, for the utilization dimension of food security, the indicator to measure it is the population that can get access to clean potable water. The final dimension of food security is stability, where the measurements are based on political instability and corruption problem. The variable to measure the improvement of food security is based on Dietary Energy Supply (DES). The food security (FS) improvement model is shown as follows:

$$
F S=f(F A V s, F A C s, F U s, F S T s)
$$

The measurement for food availability (FAVs) is based on food supply (FSP) comprising of food production (FP), food import (FM), and food aid (FA). Purchasing power parity (PPP) and road infrastructure (RI) are used to measure food accessibility (FACs), while potable clean water (PW) is used to measure food utilization (FU). Finally, food stability (FST) is based on political instability (PSR) and corruption (CTN).

$$
\begin{aligned}
& F A V s=f(F P, F M, F A)=F S P \\
& F A V s=f(F S P) \\
& F A C s=f(R I, P P P) \\
& F U=f(P W)
\end{aligned}
$$




$$
F S T=f(P S R, C T N)
$$

The proxy of food security (FS) at the national level is Dietary Energy Supply (DES). The food security model is as follows:

$$
\begin{aligned}
& \ln F S_{i t}=\alpha_{0}+\beta_{1} \ln F S P_{i t}+\beta_{2} \ln R I_{i t}+\beta_{3} \ln P P P_{i t}+\beta_{4} \ln P W_{i t}+\beta_{5} \ln P S R_{i t}+ \\
& \beta_{6} \ln C T N_{i t}+\mu_{r}+\tau_{t}+\varepsilon_{i t}
\end{aligned}
$$

\section{Data Description}

The analysis was conducted by compiling balanced panel datasets from 27 landlocked developing countries for the period of 2012 to 2018. These datasets were obtained from the FAO databases. The dependent variable was food security, whereby the proxy to measure food security was Dietary Energy Supply (DES). Meanwhile, the independent variables were food supply index (FSP), road infrastructure index (RI), purchasing power parity (PPP), population with potable water $(\mathrm{PW})$, political instability index (PSR), and corruption (CTN).

\section{Empirical Results}

Generally, the first dimension of food security is known as food availability where the indicator to measure food availability is food supply. Food supply consists of food production, food import, and food aid. The table above shows that food supply positively significant regarding the impact on food security in Landlocked Developing Countries where 1 percent in food supply will increase 0.1170 percent in food security. Increases in food supply has reduced the proportion of hunger in the world and increases food security (Godfray et al., 2010).

The next dimension of food security is accessibility. Accessibility of food is very important to ensure the availability of food is sufficient at a national level. Food access is divided into two types: physical access and economic access. Physical access consists of facilities of infrastructure, such as transportation, roads, railways, and communication. The second type of food accessibility is economics access, such as price, income, and purchasing power. Table 1 below shows the analysis of food accessibility in terms of physical access through the use of road infrastructure as a proxy to measure physical access. The analysis has shown that road infrastructure has a positive significant impact on the food security, where a 1 percent increase in road infrastructure will increase food security by 0.0285 percent. Physical access is very important to the households to sell their products and to purchase their food to fulfil their basic needs and to increase food security. Poor physical access in terms of road infrastructure is caused by several factors, such as a lack of proper roads, seasonal problems like floods and landslides, and poorly maintained roads. Well-maintained road infrastructure serves to help developing countries to achieve improved food security (IFAD, 2001). In addition, the second type of food accessibility is economic access. This analysis has adopted GDP per capita and Purchasing Power Parity (PPP) as proxies to measure the economic access of food security. This analysis has found that purchasing power parity are not significant to give an impact on food security Landlocked Developing Countries. 
Table 1: The Impact of Food Security Dimensions on Dietary Energy Supply (DES) Dependent Variables / Independents Variables DES

\begin{tabular}{lcc}
\multicolumn{2}{c}{ Dependent Variables / Independents Variables } & DES \\
\hline Food Supply (FS) & Food Availability & $0.1170^{*}$ \\
\hline & & \\
\hline Road Infrastructure (RI) & Food Accessibility & $0.0285^{*}$ \\
Purchasing Power (PPP) & 0.1103
\end{tabular}

\begin{tabular}{lc}
\hline \multicolumn{2}{c}{ Food Utilization } \\
\hline Potable Water (PW) & $0.9292^{* * *}$ \\
\hline Political Instability (PSR) & \\
& Food Stability \\
Corruption (CTN) & $-0.0028^{* *}$ \\
& \\
Intercept & $-0.0495^{* * *}$ \\
Observation & $2.6179^{* * *}$ \\
Countries & 158 \\
R-square & 27 \\
F-Test & 0.012 \\
Breusch \& Pagan Lagrangian multiplier & $132.35^{* * *}$ \\
Hausman fixed & $402.21 * * *$ \\
$*, * *$, and $* * *$ significant in 10\%, 5\%, and 1\%, respectively & $89.79 * * *$
\end{tabular}

Food Utilization is the third dimension of food security. Food utilization is very crucial to sustained food security. In other words, better utilization of food and food security can be achieved through sufficiency of diet, clean drinking water, better sanitation facilities, and good health care. This research has used the percentage of population with access to portable water. Based on the analysis, its illustrate that the percentage of population with access to portable water was positively significant give an impact to food security where 1 percent increase in population access in portable water will increase 0.9292 percent food security in landlocked developing countries. Safe and readily available water is important for public health, whether it is for drinking, domestic use, food production or recreational purposes. Improved water supply will improve food security and can boost countries' economic growth and contribute greatly to reduction of poverty and undernourishment.

Finally, last dimension of food security is known as food stability. This paper used political instability and corruption as indicator to measure food stability. The analysis shows that political instability and corruption has negatively significant impact on food security where I percent increase in political instability problem will reduce food security as much 0.0028 percent and this result same as corruption where 1 percent increase in corruption problem will reduce food security almost 0.0495 percent. 


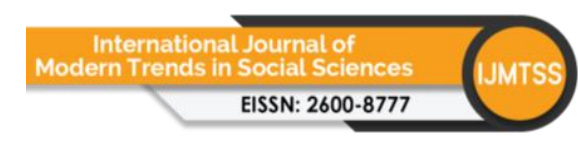

Volume 3 Issue 14 (December 2020) PP. 116-128

DOI 10.35631/IJMTSS.3140010

\section{Conclusion}

In conclusion, food security is a crucial issue for national development and poverty alleviation and has been the main goal for many international and national organizations. The United States Agency International Development (USAID) has defined food security based on four important dimensions of food security i.e. food availability, food accessibility, food utilization, and food stability. Sufficient quantities of food for all individuals within a country is known as food availability. Food availability consists of food production, food import, and food aid and is also known as food supply. Next, is food accessibility, which ensures that all individuals have access to adequate resources to get sufficient food to fulfill nutritional needs. There are two types of access namely physical access in terms of road infrastructure and economic access in terms of purchasing power. The next dimension of food security based on USAID policy is known as utilization, whereby food utilization is in term of improved in water supply very important to sustained food security and boost economic growth. Finally, improvement in political stability and decreasing in corruption problem will enhanced food security in landlocked developing countries.

This study has shown that food availability in terms of food supply gives a positive impact on food security through DES. Next, is food access, whereby improvement in road infrastructure will increase physical access plus directly giving a positive impact to DES. Moreover, food utilization in which achievement in potable water in terms of water used will improve food utilization and food security in developing countries. Finally, stability in terms of politics and reduction in corruption will improve DES in landlocked developing countries.

\section{References}

Ahmad, R. U. (1988). Rice Price Stabilization and Food Security in Bangladesh. World Development, 16(9), 1035-1050.

Breisinger, et.al,. (2010). Food as The Basis for Development and Security A Strategy for Yemen. International Food Policy Research Institute, December.

Burney, J. a., \& Naylor, R. L. (2012). Smallholder Irrigation as a Poverty Alleviation Tool in Sub-Saharan Africa. World Development, 40(1), 110-123.

Carruthers, et. al,. (1997). Irrigation and Food Security in The 21st Century. Irrigation and Drainage Systems, 11, 83-101.

Chen, R. S., \& Kates, R. W. (1994). World Food Security : Prospects and Trends. Food Policy, 19(2), 192-208.

Conceicao, et. al,. (2011). Food Security and Human Development in Africa: Strategic Considerations and Directions for Further Research. African Development Review, 23(2), 237-246.

Del Ninno, C., Dorosh, P. a., \& Subbarao, K. (2007). Food Aid, Domestic Policy and Food Security: Contrasting Experiences from South Asia and Sub-Saharan Africa. Food Policy, 32(4), 413-435.

Dong, X., Veeman, T. S., \& Veeman, M. M. (1995). China's Grain Imports: An Empirical Study. Food Policy, 20(4), 323-338.

FAO. (2019). Food Security And Nutrition In The World.

Haddad, L., Kennedy, E., \& Sullivan, J. (1994). Choice of Indicators for Food Security and Nutrition Monitoring. Food Policy, 19(3), 329-343.

Hassan, R. M., Faki, H., \& Byerlee, D. (2000). The Trade-Off Between Economic Efficiency and Food Self-Sufficiency in Using Sudan's Irrigated Land Resources. Food Policy, 25(1), 35-54. 
Howard, G., \& Bartram, J. (2003). Domestic Water Quantity, Service Level And Health.

Hubbard, et. al., (2011). A Community Demand-Driven Approach Toward Sustainable Water and Sanitation Infrastructure Development. International Journal of Hygiene and Environmental Health, 214(4), 326-334.

Kennedy, G., Nantel, G., \& Shetty, P. (2004). Globalization of Food Systems in Developing Countries: A Synthesis of Country Case Studies.

Magnan, et. al,. (2011). Modeling The Limitations and Implicit Costs of Cereal SelfSufficiency: The Case of Morocco. Food Security, 3(S1), 49-60.

Mara, D. D. (2003). Water, Sanitation and Hygiene For The Health of Developing Nations. Public Health, 117(6), 452-456.

Morrison, T. K. (1984). Cereal Imports by Developing Countries Rends and Determinants. Food Policy.

Myers, R. J. (2006). On The Costs of Food Price Fluctuations In Low-Income Countries. Food Policy, 31(4),

USAID. (1992). Policy Determination: Definition Of Food Security. PD-19.

Wagstaff, H. (1982). Food Imports Of Developing Countries. Food Policy.

Wang, J. (2010). Food Security, Food Prices and Climate Change In China: A Dynamic Panel Data Analysis. Agriculture And Agricultural Science Procedia, 1(December 2009), 321-324.

Watson, T. (2006). Public Health Investments And The Infant Mortality Gap: Evidence From Federal Sanitation Interventions On U.S. Indian Reservations. Journal Of Public Economics, 90(8-9), 1537-1560.

World Bank. (1997). Poverty Assessment : Constraints To Rural Development (Issue 16567).

World Food Programmed. (2007). Strengthening Emergency Needs Assessment Capacity (Issue December 2006).

WTO. (1998). Understanding The Sanitary and Phytosanitary Measures Agreement. In World Trade Orgnization. Http://Www.Wto.Org/English/Tratop_E/Sps_E/Spsund_E.Htm

Zhang, J. (2011). China's Success In Increasing Per Capita Food Production. Journal Of Experimental Botany, 62(11), 3707-3711. 